\title{
Effectiveness and Effect on Renal Parameters of Amlodipine vs. Other Dihydropyridine Calcium Channel Blockers in Patients with Essential Hypertension: Retrospective Observational Study Based on Real-World Evidence from Electronic Medical Records
}

Uday Jadhav · Padhinhare P. Mohanan · Alan Fernandes Almeida - Georgi Abraham • Mohammed Yunus Khan · Kumar Gaurav · Amey Mane $\cdot$ Seema Vikas $\cdot$ Madhur Jain · Bhavesh Meel

Received: March 30, 2021 / Accepted: May 24, 2021 / Published online: June 11, 2021

(C) The Author(s) 2021

\section{ABSTRACT}

Introduction: The renoprotective effects of dihydropyridine calcium channel blockers (CCBs) have been established as non-inferior to other classes of antihypertensive drugs. Studying their effect on renal outcome parameters,

Supplementary Information The online version contains supplementary material available at https:// doi.org/10.1007/s40119-021-00224-8.

\section{U. Jadhav}

Cardiology Department, MGM New Bombay

Hospital, Mumbai, India

e-mail: umjadhav@gmail.com

P. P. Mohanan

Westfort Hi-Tech Hospital, Thrissur, Kerala, India

e-mail: drppmohanan@gmail.com

A. F. Almeida

PD Hinduja Hospital and Medical Research Center, Mumbai, India

e-mail: almeidaa@gmail.com

G. Abraham

MGM Healthcare, Nelson Manickam Road,

Aminjikarai, Chennai, India

e-mail: abrahamgeorgi@yahoo.com

M. Y. Khan $(\varangle) \cdot$ K. Gaurav · A. Mane · S. Vikas

Medical Affairs, Dr. Reddy's Laboratories Ltd,

Hyderabad, India

e-mail: doctorkhan26@gmail.com specifically for amlodipine as monotherapy, in real-world settings can further help in expanding its usage among Indian patients. This study was performed to assess the effects of amlodipine and other dihydropyridine CCBs (cilnidipine, benidipine and azelnidipine) on renal parameters and effectiveness in blood pressure reduction in Indian patients.

Methods: The retrospective data of adult patients ( $>18$ years) with essential hypertensive who were prescribed amlodipine $(n=92)$, cil-

\section{K. Gaurav}

e-mail: Kumargaurav2@drreddys.com

\author{
A. Mane \\ e-mail: amey.mane@drreddys.com \\ S. Vikas \\ e-mail: seemavikasb@drreddys.com \\ M. Jain \\ Ujala Cygnus Super Specialty Hospital, Rewari, \\ Haryana, India \\ e-mail: dr.madhurjain1@gmail.com \\ B. Meel \\ Heart and General Hospital, Jaipur, Rajasthan, India \\ e-mail: bhavesh_meel@rediffmail.com
}


nidipine $(n=91)$, benidipine $(n=70)$ or azelnidipine $(n=71)$ as monotherapy were analyzed. The renal outcomes, serum creatinine, estimated glomerular filtration rate (eGFR), blood urea nitrogen (BUN), microalbumin, urine albumin-to-creatinine ratio (UACR), sodium and potassium levels, and mean changes in BP were analyzed from baseline to 12 months. Appropriate statistical methods were used to determine the significance ( $p$ value $<0.05)$.

Results: From baseline to the end of the study, mean serum creatinine changed from $0.98 \pm 0.17$ to $1.07 \pm 0.28 \mathrm{mg} / \mathrm{dL}$ with amlodipine, $0.97 \pm 0.18$ to $1.13 \pm 0.50 \mathrm{mg} / \mathrm{dL}$ with cilnidipine, $0.98 \pm 0.30$ to $0.97 \pm 0.27 \mathrm{mg} / \mathrm{dL}$ wi th benidipine, and $0.99 \pm 0.23$ to $0.98 \pm 0.25 \mathrm{mg} / \mathrm{dL}$ with azelnidipine $(p=0.01)$. The mean microalbumin and UACR were reduced from baseline to the end of the study ( $p=0.06$ and $p>0.05$ ). No significant changes were observed in BUN, sodium or potassium levels. Overall, for all CCBs, the mean systolic blood pressure (SBP) and diastolic blood pressure (DBP) values were reduced from baseline to the end of the study $(p=0.002)$. At the end of the study, the average dose of amlodipine was $7.25 \mathrm{mg}$, and the average reduction in SBP and DBP per mg dose was 1.54 and $0.57 \mathrm{mmHg}$. The corresponding numbers for the other CCBs were as follows: cilnidipine, $14.28 \mathrm{mg}, 0.26$ and 0.01 ; benidipine, $5.71 \mathrm{mg}$, 0.41 and 0.11 ; azelnidipine, $15.88 \mathrm{mg}, 0.13$ and 0.06 .

Conclusion: Amlodipine and other CCBs demonstrated good efficacy and similar effects on renal parameters from baseline to end of study. Amlodipine also showed higher potency by demonstrating greater BP reduction at a lower dose. Thus, amlodipine can remain a preferred choice among CCBs, even with the advent of the newer CCBs.

Keywords: Amlodipine;

Cilnidipine; Benidipine; Azelnidipine; EMR; Renal outcome

\section{Key Summary Points}

This study shows that amlodipine can remain a preferred choice among CCBs even with the advent of newer CCBs.

In this study, amlodipine had similar efficacy and effects on renal parameters as those shown by newer multichannelblocking CCBs.

This effect was observed with all doses of amlodipine reported in the study throughout the study duration.

The extent of reduction in SBP and DBP increased gradually at each consecutive visit in the amlodipine group.

The average effectiveness per mg dose of amlodipine also showed a similar pattern.

\section{DIGITAL FEATURES}

This article is published with digital features, including a summary slide to facilitate understanding of the article. To view digital features for this article go to https://doi.org/10.6084/ m9.figshare.14627349.

\section{INTRODUCTION}

According to the European Society of Cardiology/European Society of Hypertension (ESC/ ESH) 2018 guidelines and the Indian Guidelines on Hypertension (IGH) IV [1], hypertension is defined as a pathophysiological condition characterized by systolic blood pressure (SBP)/diastolic blood pressure (DBP) of $\geq 140$ / $90 \mathrm{mmHg}$. Elevated SBP is reported as the leading global risk factor, accounting for 10.2 million deaths $[1,2]$. Hypertension is both a cause and effect of chronic kidney disease (CKD) and end-stage renal disease (ESRD), as uncontrolled blood pressure may lead to kidney damage (the presence of proteinuria for $\geq 3$ months 
duration) [3-7]. Management of hypertension helps to slow the progression of CKD and ESRD [3-8].

Calcium channel blockers (CCBs) are the first-line antihypertensive treatment for essential hypertension. Besides the antihypertensive effect, CCBs have also been reported to exhibit renoprotective effects [9]. The ancillary effect of CCBs stems from the renal sympathetic nerve activity inhibition, which further triggers efferent arteriolar vasodilation and thus protects the glomeruli through the attenuation of glomerular hypertension [9]. However, this effect is not shown by L-type CCBs, but by $\mathrm{N}$ - and T-type CCBs [10]. Compared to the short-acting CCBs, the long-acting CCBs are beneficial due to the lower ability to activate the sympathetic nervous system.

Clinical and experimental data have indicated renoprotective differences among the classes of CCBs [11-13]. Amlodipine inhibits the slow L-type voltage-gated calcium channels, with slow absorption $\left(T_{\max }=6 \mathrm{~h}\right)$ and longer half-life $\left(t_{1 / 2}=30-60 \mathrm{~h}\right)$ [14]. Benidipine inhibits L-, $\mathrm{N}$ - and T-type calcium channels. It has a $T_{\max }$ of $2 \mathrm{~h}$. Cilnidipine inhibits L- and N-type calcium channels, with $T_{\max }$ of $2 \mathrm{~h}$ and a halflife of $2.5 \mathrm{~h}$. Azelnidipine inhibits both L- and T-type calcium channels. It shows dose-dependent $T_{\max }$ of $3 \mathrm{~h}$ and has a half-life of $16-18 \mathrm{~h}$ [15].

Several clinical studies have demonstrated renoprotective effects of the newer generation of CCBs (cilnidipine, benidipine and azelnidipine) [16-19], and so it is important to compare the longitudinal renoprotective effect of amlodipine with the other CCBs (benidipine, cilnidipine and azelnidipine). Studying their renal effects as mono-therapy in real-world settings can further help in expanding their realm of usage among Indian patients. In this realworld evidence (RWE) study, the renal parameters of patients on amlodipine were compared with other CCBs (cilnidipine, benidipine and azelnidipine) in Indian patients with essential hypertension.

\section{METHODS}

\section{Study Design}

In this retrospective, longitudinal, real-world observational study, the electronic medical records (EMR) of Indian patients diagnosed with essential hypertension from April 2014 to May 2019 were collected from multiple tertiary care cardiology departments.

\section{Sample Size Calculation}

A statistical power analysis projected a minimum sample size of $N=180$ (45 in each group) for the comparison between groups to achieve power of $99 \%$.

\section{Data Sources and Study Sample}

The study included adult patients ( $\geq 18$ years) diagnosed with essential hypertension by their physicians and prescribed amlodipine, cilnidipine, benidipine or azelnidipine as the firstline monotherapy, and had follow-up data available for a minimum of 3-12 months following the baseline visit after initiation of treatment.

Patients diagnosed with severe hypertension (BP > 180/110 mmHg), secondary hypertension such as in obstructive sleep apnea, atherosclerotic renovascular disease, fibromuscular dysplasia, primary aldosteronism, pheochromocytoma, Cushing's syndrome, thyroid disease (hypo/hyperthyroidism, hyperparathyroidism, renal parenchymal disease), severe renal failure (estimated glomerular filtration rate $[\mathrm{eGFR}]<30 \mathrm{~mL} / \mathrm{min}$ ) and patients on CCBs other than amlodipine, cilnidipine, benidipine or azelnidipine at visit 1 (baseline) were excluded from the study. Additionally, pregnant and lactating women were also excluded from the study.

\section{Ethics}

An independent ethics committee (IEC) located in Pune, India (Royal Pune Independent Ethics 
Committee, with registration number ECR/45/ Indt/MH/2013/RR-19) approved the study protocol. This was a retrospective study and used anonymized data (existing medical records available as of the date of IEC submission) without any additional prospective components for research purposes. Hence, the process did not require us to obtain informed consent, since the study did not involve identifiable individuals. Accordingly, IEC waived the requirement for informed consent form before the initiation of the data collection process for this study. The study was conducted in compliance with ethics guidelines and in accordance with the Helsinki Declaration of 1964 and its later amendments.

\section{Statistical Analysis}

All outcomes are presented using descriptive statistics. Continuous data are expressed as mean and SD and categorical data as numbers and percentages. Mean differences in the data were analyzed by the Mann-Whitney $U$ test/ $t$ test and categorical variables by the chi-square test. ANOVA was used for testing the significant difference between more than two groups. A $p$ value $<0.05$ was considered statistically significant to determine the difference between amlodipine and the other CCBs.

\section{Assessment}

\section{Baseline Characteristics}

Data consisting of demographic characteristics including age, gender, personal and family history, and clinical features including the grade of hypertension as per ESC/ESH 2018 guidelines, $\mathrm{BP}$ readings, comorbidities, and concomitant medications were collected at baseline and are reported.

\section{CCB Effectiveness Analysis}

For evaluating the effectiveness of the study drugs as antihypertensives, the EMR data including baseline data and the follow-up data up to the end of 12 months (study period) were analyzed for all four CCBs. The definitions of effectiveness parameters are given in the supporting information.

\section{CCB Tolerability Assessment}

For evaluating renal tolerability, renal parameters (serum creatinine, eGFR, microalbumin, blood urea nitrogen [BUN], urine albumin-tocreatinine ratio [UACR]/microalbuminuria, and sodium and potassium levels) for each of the CCBs were assessed from baseline to last followup visit up to 12 months or until the time that amlodipine, cilnidipine, benidipine or azelnidipine was discontinued or newer therapy added or up to the end of the study period, whichever occurred earlier.

The definitions of tolerability parameters are given in the supporting information. The sample considered in the study is depicted in Fig. 1.

\section{RESULTS}

\section{Baseline Demographics}

The average age in the amlodipine, cilnidipine, benidipine and azelnidipine groups was $58.4 \pm 7.9, \quad 55.6 \pm 9.9, \quad 63.2 \pm 6.5 \quad$ and $49.9 \pm 9.1$ years, respectively. The proportion of men was higher than that of women across groups, $>63 \%$. The basal metabolic index (BMI) values varied slightly within a range of $1-4$ units (Table 1). In all groups, at baseline, headache was the primary complaint reported by patients as hypertensive symptom, followed by palpitation and fatigue. The baseline mean SBP was comparable across the four groups, and the mean DBP varied on average by $\pm 1.9 \mathrm{mmHg}$ among the four groups. Based on the ESC/ESH 2018 guidelines, overall $>68 \%$ patients had grade 1 hypertension and the rest had grade 2 (Table 1).

Obesity, diabetes and dyslipidemia were the three most frequently reported comorbidities, and kidney disease was reported only in the benidipine group $(n=2)$. The amlodipine group had the smallest number of obese patients among all the groups. About $>14 \%$ and $>18 \%$ patients had maternal and paternal hypertension, respectively (Table 1). 


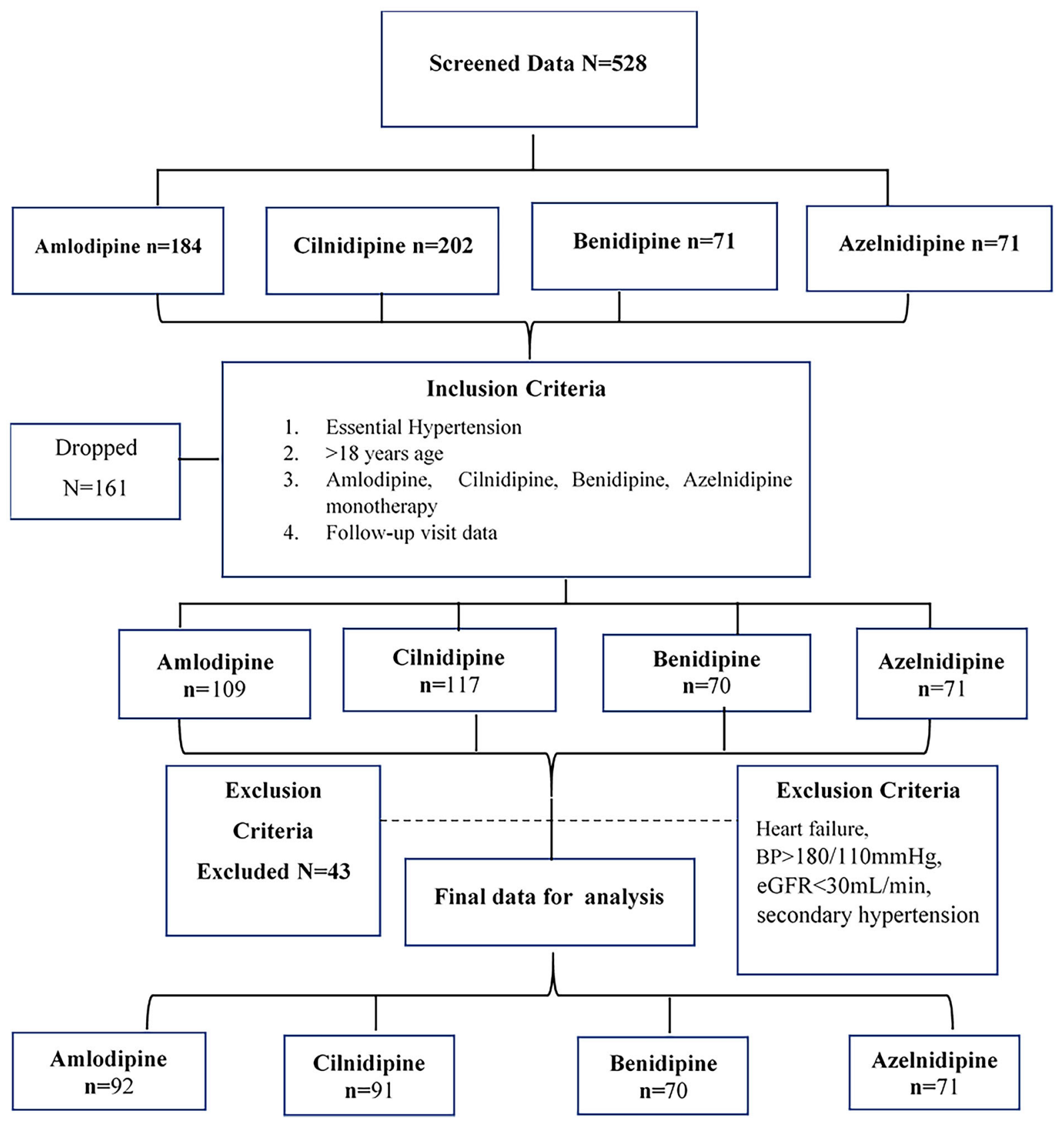

Fig. 1 Study sample selection flowchart

A common pattern observed in all the groups was an increase in the mean doses of CCBs throughout the study period (Table 2).

The results are presented as follows: The overall change in renal parameters for the four CCBs was analyzed comparatively to determine clinical and statistical significance, with an emphasis on the specific parameters serum creatinine, eGFR, albumin, BUN and UACR. This was followed by effectiveness analysis in terms of overall mean reduction in SBP and DBP and potency of CCBs analyzed as reduction in mean BP per $\mathrm{mg}$ dose, and lastly tolerability outcomes of $\mathrm{CCB}$ treatment according to whether patients 
Table 1 Baseline demographic profile $(N=324)$

\begin{tabular}{|c|c|c|c|c|c|}
\hline Parameter name & $\begin{array}{l}\text { Amlodipine } \\
(N=92)\end{array}$ & $\begin{array}{l}\text { Cilnidipine } \\
(N=91)\end{array}$ & $\begin{array}{l}\text { Benidipine } \\
(N=70)\end{array}$ & $\begin{array}{l}\text { Azelnidipine } \\
(N=71)\end{array}$ & $p$ value \\
\hline Age (years) $($ mean $\pm S D)$ & $58.41 \pm 7.93$ & $55.56 \pm 9.92$ & $63.17 \pm 6.54$ & $49.97 \pm 9.12$ & $<0.0001$ \\
\hline \multicolumn{6}{|l|}{ Gender $(n \%)$} \\
\hline Male & $65(70.65)$ & $71(78.02)$ & $55(78.57)$ & $45(63.38)$ & \multirow[t]{2}{*}{0.12} \\
\hline Female & $27(29.35)$ & $20(21.98)$ & $15(21.43)$ & $26(36.62)$ & \\
\hline Weight $(\mathrm{kg})($ mean $\pm \mathrm{SD})$ & $68.90 \pm 9.30$ & $71.48 \pm 8.92$ & $77.37 \pm 12.97$ & $73.42 \pm 10.98$ & $<0.0001$ \\
\hline Height $(\mathrm{m})($ mean $\pm S D)$ & $166.62 \pm 6.38$ & $165.45 \pm 6.09$ & $162.66 \pm 5.48$ & $162.69 \pm 3.05$ & $<0.0001$ \\
\hline $\operatorname{BMI}\left(\mathrm{kg} / \mathrm{m}^{2}\right)($ mean $\pm \mathrm{SD})$ & $24.88 \pm 3.47$ & $26.05 \pm 3.56$ & $29.26 \pm 4.81$ & $27.76 \pm 4.29$ & $<0.0001$ \\
\hline \multicolumn{6}{|c|}{ Hypertension complaints reported at baseline, $n$ (\%) } \\
\hline Headache & $65(70.65)$ & $61(67.78)$ & $31(44.29)$ & $36(50.70)$ & NA \\
\hline Palpitation & $22(23.91)$ & $38(42.22)$ & $4(5.71)$ & $26(36.62)$ & NA \\
\hline Fatigue & $19(20.65)$ & $33(36.67)$ & ND & $27(38.03)$ & NA \\
\hline Chest pain & $6(6.52)$ & $33(36.67)$ & $7(10.00)$ & $38(53.52)$ & NA \\
\hline Dyspnea (on exertion) & ND & $45(50.00)$ & $16(22.86)$ & $51(71.83)$ & NA \\
\hline Dizziness & $13(14.13)$ & $6(6.67)$ & $21(30.00)$ & $9(12.68)$ & NA \\
\hline Lightheadedness & $14(15.22)$ & ND & $17(24.29)$ & ND & NA \\
\hline Nervousness & $13(14.13)$ & $7(7.78)$ & ND & ND & NA \\
\hline Nasal bleed & ND & $12(13.33)$ & ND & $18(25.35)$ & NA \\
\hline Tinnitus & $10(10.87)$ & ND & $10(14.29)$ & ND & NA \\
\hline \multicolumn{6}{|l|}{ Baseline BP, mean $( \pm S D)$} \\
\hline Baseline SBP (mmHg) & $152.56 \pm 10.91$ & $152.38 \pm 10.46$ & $152.59 \pm 10.52$ & $150.24 \pm 10.49$ & 0.468 \\
\hline Baseline DBP (mmHg) & $95.63 \pm 6.02$ & $92.85 \pm 7.27$ & $94.09 \pm 6.62$ & $95.95 \pm 5.97$ & 0.006 \\
\hline Baseline resting heart rate $(\mathrm{bpm})$ & $82.32 \pm 8.59$ & $83.35 \pm 10.53$ & $85.83 \pm 12.89$ & $80.53 \pm 11.05$ & 0.029 \\
\hline Duration of illness (days/years) & $11.18 \pm 12.38$ & $56.78 \pm 132.73$ & $10.60 \pm 9.04$ & ND & 0.0001 \\
\hline \multicolumn{6}{|c|}{ Grade of hypertension (as per ESC/ESH 2018 guidelines) } \\
\hline Grade 1 & $63(69.23)$ & $63(70.00)$ & $48(68.57)$ & $53(74.65)$ & 0.819 \\
\hline Grade 2 & $28(30.77)$ & $28(31.11)$ & $22(31.43)$ & $18(25.35)$ & 0.845 \\
\hline Grade 3 & $1(1.10)$ & $0(0)$ & $0(0)$ & $0(0)$ & 0.783 \\
\hline \multicolumn{6}{|l|}{ Comorbidities and family history } \\
\hline Obesity & $15(16.30)$ & $17(18.48)$ & $29(31.52)$ & $27(29.35)$ & \\
\hline Diabetes & $8(8.70)$ & $14(15.22)$ & $5(5.43)$ & $4(4.35)$ & \\
\hline Dyslipidemia & $8(8.70)$ & $11(11.96)$ & $6(6.52)$ & $0(0.00)$ & \\
\hline
\end{tabular}


Table 1 continued

\begin{tabular}{|c|c|c|c|c|c|}
\hline Parameter name & $\begin{array}{l}\text { Amlodipine } \\
(N=92)\end{array}$ & $\begin{array}{l}\text { Cilnidipine } \\
(N=91)\end{array}$ & $\begin{array}{l}\text { Benidipine } \\
(N=70)\end{array}$ & $\begin{array}{l}\text { Azelnidipine } \\
(N=71)\end{array}$ & $p$ value \\
\hline $\begin{array}{l}\text { Heart disease (myocardial } \\
\text { infarction, coronary artery disease) }\end{array}$ & $6(6.52)$ & $5(5.43)$ & $0(0.00)$ & $0(0.00)$ & \\
\hline Stroke & $4(4.35)$ & $1(1.09)$ & $0(0.00)$ & $0(0.00)$ & \\
\hline Kidney disease $^{\mathrm{a}}$ & $0(0.00)$ & $0(0.00)$ & $2(2.17)$ & $0(0.00)$ & \\
\hline Heart failure & $0(0.00)$ & $0(0.00)$ & $1(1.09)$ & $0(0.00)$ & \\
\hline Other & $0(0.00)$ & $1(1.09)$ & $0(0.00)$ & $0(0.00)$ & \\
\hline \multicolumn{6}{|l|}{ Lifestyle-related } \\
\hline Smokers & $13(14.13)$ & $11(11.96)$ & $8(8.70)$ & $7(7.61)$ & \\
\hline Alcoholics & $10(10.87)$ & $18(19.57)$ & $62(67.39)$ & $10(10.87)$ & \\
\hline \multicolumn{6}{|l|}{ Family history of hypertension } \\
\hline Mother & $28(30.43)$ & $23(25.00)$ & $18(19.57)$ & $17(18.48)$ & \\
\hline Father & $26(28.26)$ & $25(27.17)$ & $23(25.00)$ & $13(14.13)$ & \\
\hline Other relation & $7(7.61)$ & $5(5.43)$ & $10(10.87)$ & $8(8.70)$ & \\
\hline
\end{tabular}

$N D$ not detected, $N A$ not applicable

${ }^{a}$ eGFR $>30 \mathrm{~mL} / \mathrm{min} / 1.73 \mathrm{~m}^{2}$

continued or discontinued the prescribed dose regimen or switched over to other antihypertensive drugs.

\section{Renal Parameters}

The overall renal parameters from baseline to the end of the study are given in Fig. 2. Overall, post-treatment with CCBs, no significant changes in renal parameters were observed from baseline to the end of the study. In detail, during the same time points, mean serum creatinine values changed only slightly, in the amlodipine group from $0.98 \pm 0.17$ to $1.07 \pm 0.28 \mathrm{mg} / \mathrm{dL}, \quad$ cilnidipine from $0.97 \pm 0.18$ to $1.13 \pm 0.50 \mathrm{mg} / \mathrm{dL}$, benidipine from $0.98 \pm 0.30$ to $0.97 \pm 0.27 \mathrm{mg} / \mathrm{dL}$, and azelnidipine from $0.99 \pm 0.23$ to $0.98 \pm 0.25 \mathrm{mg} / \mathrm{dL}$. The difference in mean creatinine values across the four groups at the end of the study was statistically significant $(p=0.01)$. Correspondingly, eGFR values were reduced by 5 units in the amlodipine group, from $79.82 \pm 18.44$ to $74.95 \pm 22.28 \mathrm{~mL} / \mathrm{min} /$ $1.73 \mathrm{~m}^{2}$, and the cilnidipine group from $83.58 \pm 21.47$ to $78.67 \pm 28.96$, whereas there was no noticeable change in the benidipine group, $85.06 \pm 25.62$ to $84.78 \pm 26.30$, and an increase by 2 units in the azelnidipine group, $82.35 \pm 24.16$ to $84.05 \pm 28.24 \mathrm{~mL} / \mathrm{min} /$ $1.73 \mathrm{~m}^{2}$. The difference in mean eGFR values of across the four groups at the end of the study was not statistically significant $(p=0.06)$.

The baseline mean BUN values were higher for the other three groups than for the amlodipine group. Following the CCB treatment, from baseline to the end of the study, the mean values for the amlodipine group were $18.93 \pm 6.80$ to $20.72 \pm 9.62 \mathrm{mg} / \mathrm{dL}$, for cilnidipine, $23.22 \pm 6.82$ to $24.77 \pm 8.99$, benidipine, $26.56 \pm 9.13$ to $27.28 \pm 10.20$, and azelnidipine, $\quad 25.79 \pm 10.19 \quad$ to $25.88 \pm 10.66 \mathrm{mg} / \mathrm{dL}$. The difference in mean values across the groups was statistically significant at the end of the study $(p=0.0002)$. 
Across groups, from baseline to end of study, no significant change in mean microalbumin or UACR values (all $p>0.05$ ) was observed.

The overall mean sodium and potassium values, from baseline to the end of the study, were within the normal range (135-145 mEq/L and 3.6 to $5.2 \mathrm{mmol} / \mathrm{L}$ ) across the groups (Fig. 2).

Further subgroup analysis of dose vs. mean renal outcomes was performed for the parameters of serum creatinine, eGFR and UACR across the four groups. The considered doses for amlodipine were $2.5,5$ and $10 \mathrm{mg}$, cilnidipine, 5,10 and $20 \mathrm{mg}$, benidipine, 2, 4, $8 \mathrm{mg}$, and azelnidipine, 8 and $16 \mathrm{mg}$. Due to varying doses, no overall comparison can be drawn across the groups; however, inferences within the groups are given. Overall, for all doses, no significant change in mean serum creatinine values was observed for amlodipine, benidipine or azelnidipine, but for cilnidipine, the overall mean serum creatinine value increased from 0.83 to $1.10 \mathrm{mg} / \mathrm{dL}$ for the $5 \mathrm{mg}$ dose. Overall, for all doses of all CCBs, mean eGFR and UACR values were reduced from baseline to the end of the study (Fig. 3).

\section{Effectiveness of CCB Treatment}

Overall, for all CCBs, the mean SBP and DBP values were reduced from baseline to the end of the study (Fig. 4): amlodipine, $152.56 \pm 10.91$ to $\quad 126.80 \pm 12.44 \mathrm{mmHg}$; cilnidipine, $152.38 \pm 10.46$ to $127.12 \pm 17.87 \mathrm{mmHg}$; benidipine, $152.59 \pm 10.52$ to $124.16 \pm 11.28$ $\mathrm{mmHg}$; and azelnidipine, $150.24 \pm 10.49$ to $120.75 \pm 22.76 \mathrm{mmHg}$. The difference in mean $\mathrm{BP}$ values at the end of the study across the four groups was statistically significant $(p=0.002)$. As mentioned earlier, the patient follow-up data were captured at four intervals during the study period from the baseline visit. The reduction in

Table 2 Interventional drug details $(N=324)$

\begin{tabular}{|c|c|c|c|c|}
\hline Interventional drug & $\begin{array}{l}\text { Amlodipine } \\
(N=92) \\
\text { mean }( \pm \text { SD })\end{array}$ & $\begin{array}{l}\text { Cilnidipine } \\
(N=91) \\
\text { mean }( \pm \text { SD })\end{array}$ & $\begin{array}{l}\text { Benidipine } \\
(N=70) \\
\text { mean }( \pm \text { SD })\end{array}$ & $\begin{array}{l}\text { Azelnidipine } \\
(N=71) \\
\text { mean }( \pm S D)\end{array}$ \\
\hline \multicolumn{5}{|l|}{ Baseline } \\
\hline Dose of drug (mg) & $5.59 \pm 2.17$ & $8.90 \pm 2.08$ & $5.22 \pm 2.24$ & $8 \pm 0$ \\
\hline Mean duration (in days) & $49.56 \pm 28.28$ & $63.62 \pm 29.94$ & $47.14 \pm 27.30$ & $30 \pm 0$ \\
\hline \multicolumn{5}{|c|}{ Follow-up 1 (at the end of 3 months) } \\
\hline Dose of drug (mg) & $6.33 \pm 2.26$ & $14.39 \pm 4.99$ & $5.49 \pm 2.28$ & $16 \pm 0$ \\
\hline Mean duration (in days) & $90 \pm 0$ & $90 \pm 0$ & $90 \pm 0$ & $90 \pm 0$ \\
\hline \multicolumn{5}{|c|}{ Follow-up 2 (at the end of 6 months) } \\
\hline Dose of drug (mg) & $7.25 \pm 4.61$ & $14.34 \pm 5.06$ & $5.71 \pm 1.99$ & $16 \pm 0$ \\
\hline Mean duration (in days) & $90 \pm 0$ & $90 \pm 0$ & $90 \pm 0$ & $90 \pm 0$ \\
\hline \multicolumn{5}{|c|}{ Follow-up 3 (at the end of 9 months) } \\
\hline Dose of drug (mg) & $7.25 \pm 4.61$ & $14.28 \pm 5.14$ & $5.71 \pm 1.99$ & $15.88 \pm 0.95$ \\
\hline Mean duration (in days) & $90 \pm 0$ & $129.56 \pm 44.91$ & $90 \pm 0$ & $180 \pm 0$ \\
\hline \multicolumn{5}{|c|}{ Follow-up 4 (at the end of 12 months) } \\
\hline Dose of drug $(\mathrm{mg})$ & $7.33 \pm 5.20$ & $14 \pm 5.09$ & $5.49 \pm 2.17$ & $14.76 \pm 3.21$ \\
\hline Mean duration (in days) & $90 \pm 0$ & $129 \pm 44.84$ & $90 \pm 0$ & $90 \pm 0$ \\
\hline
\end{tabular}



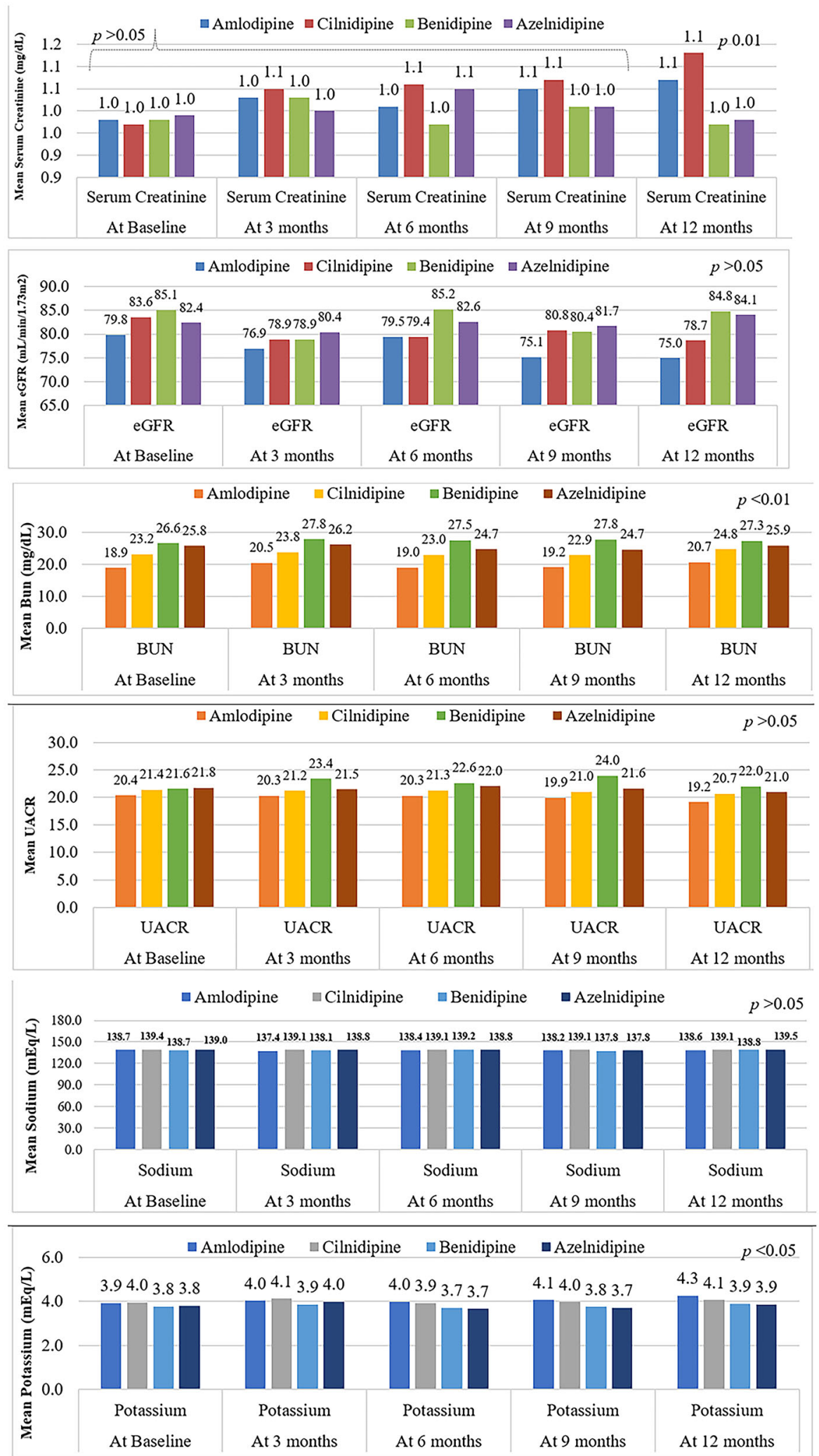

Fig. 2 Renal parameters from baseline to end of the study are given for amlodipine (91), cilnidipine (90), benidipine (70) and azelnidipine (71) 


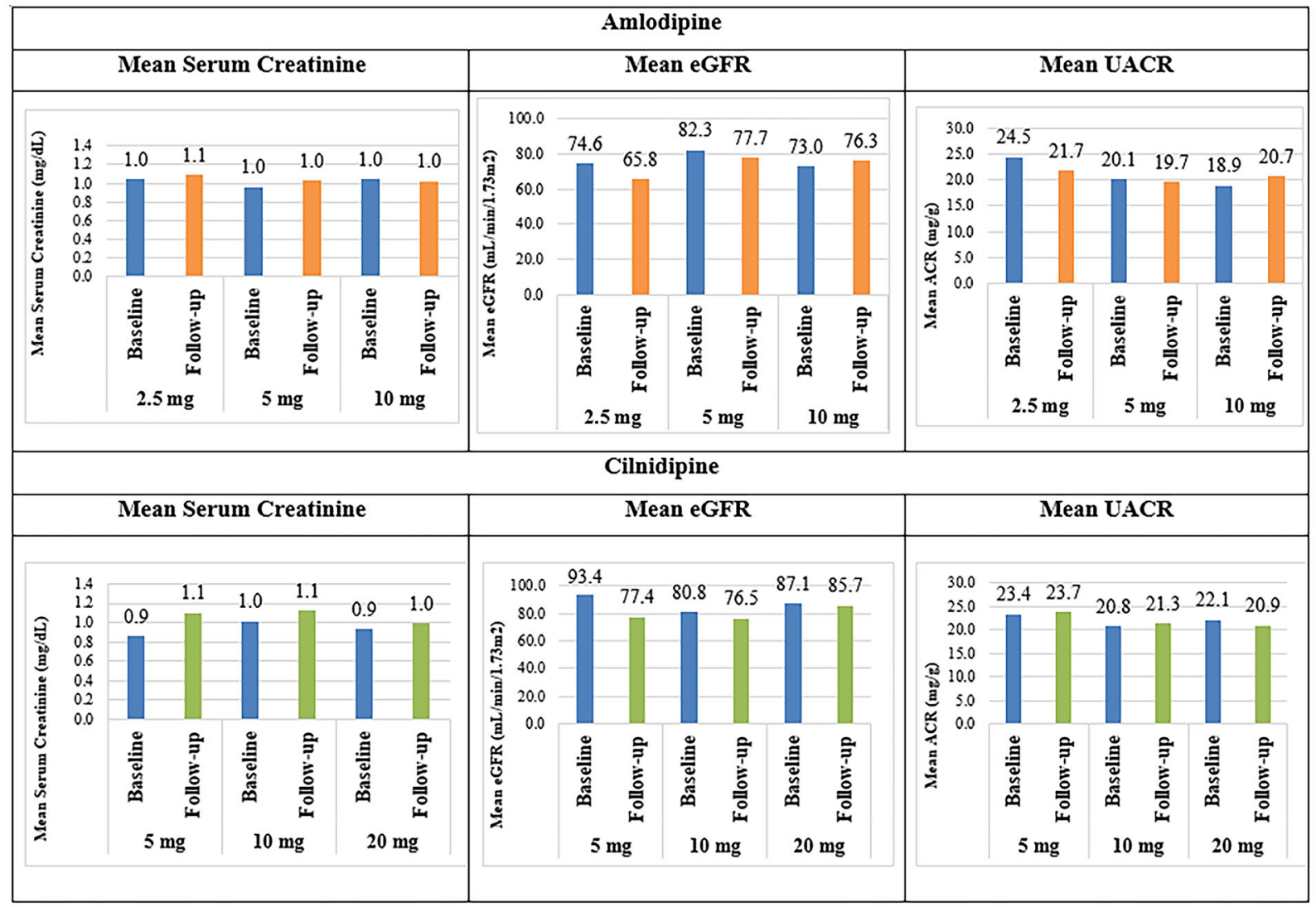

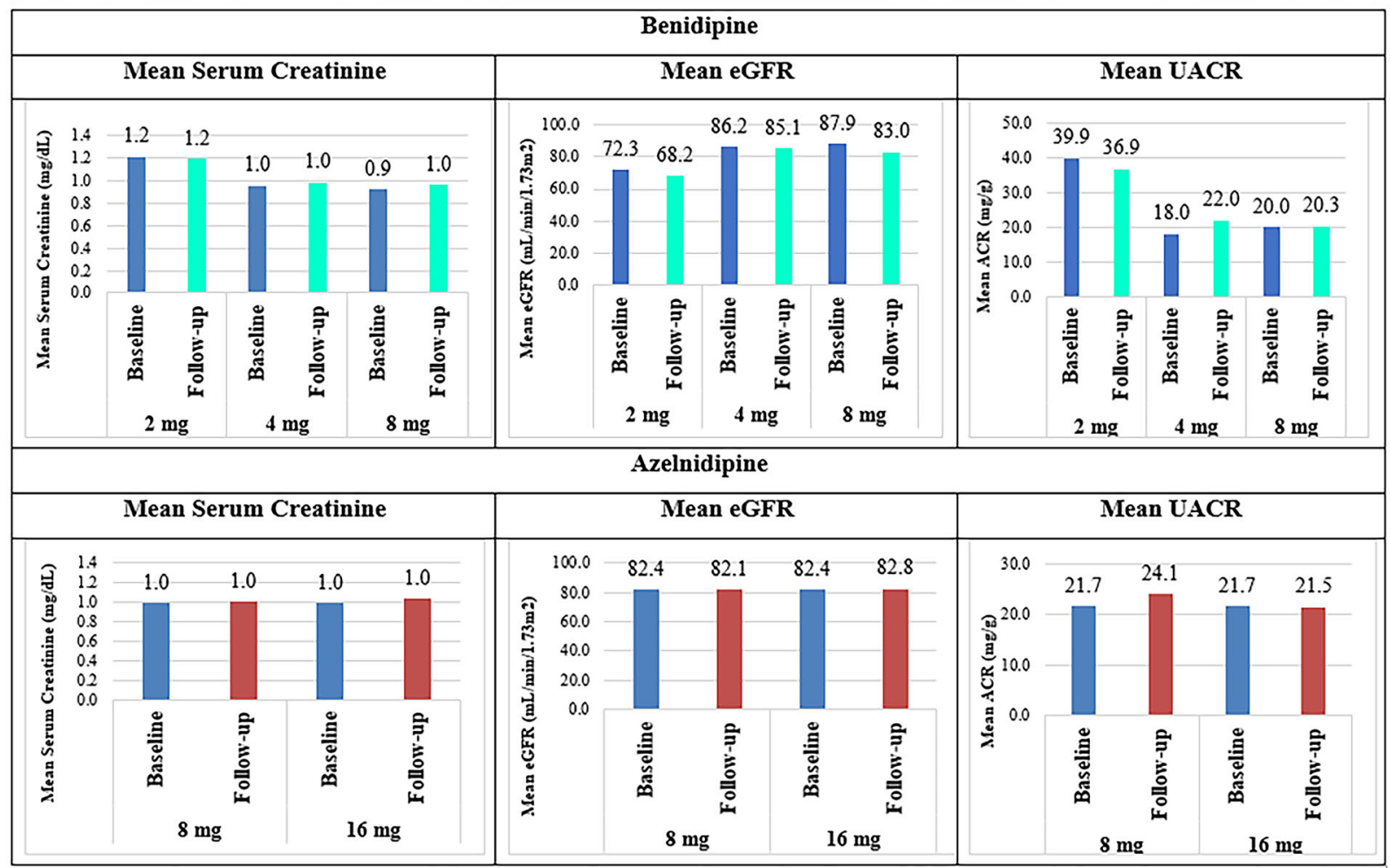


4 Fig. 3 Renal parameters, serum creatinine, eGFR and UACR values at baseline and follow-up period are given per CCB dose for amlodipine $(N=91)$, cilnidipine $(N=90)$, benidipine (70) and azelnidipine (71). The follow-up period included visits 1 (at 3 months), 2 (at 6 months), 3 (at 9 months) and 4 (end of study, i.e., 12 months)
BP was further analyzed at every visit from the baseline to the end of the study (last visit). The extent of change (reduction) in BP at every follow-up varied from CCB to CCB. For example, with amlodipine, the reduction in BP gradually improved from the first visit $(7.8 \mathrm{mmHg})$ to the last visit $(11 \mathrm{mmHg})$. In contrast, with other CCBs, the reduction was greatest at the first visit (cilnidipine, 10.46; benidipine, 13.03;

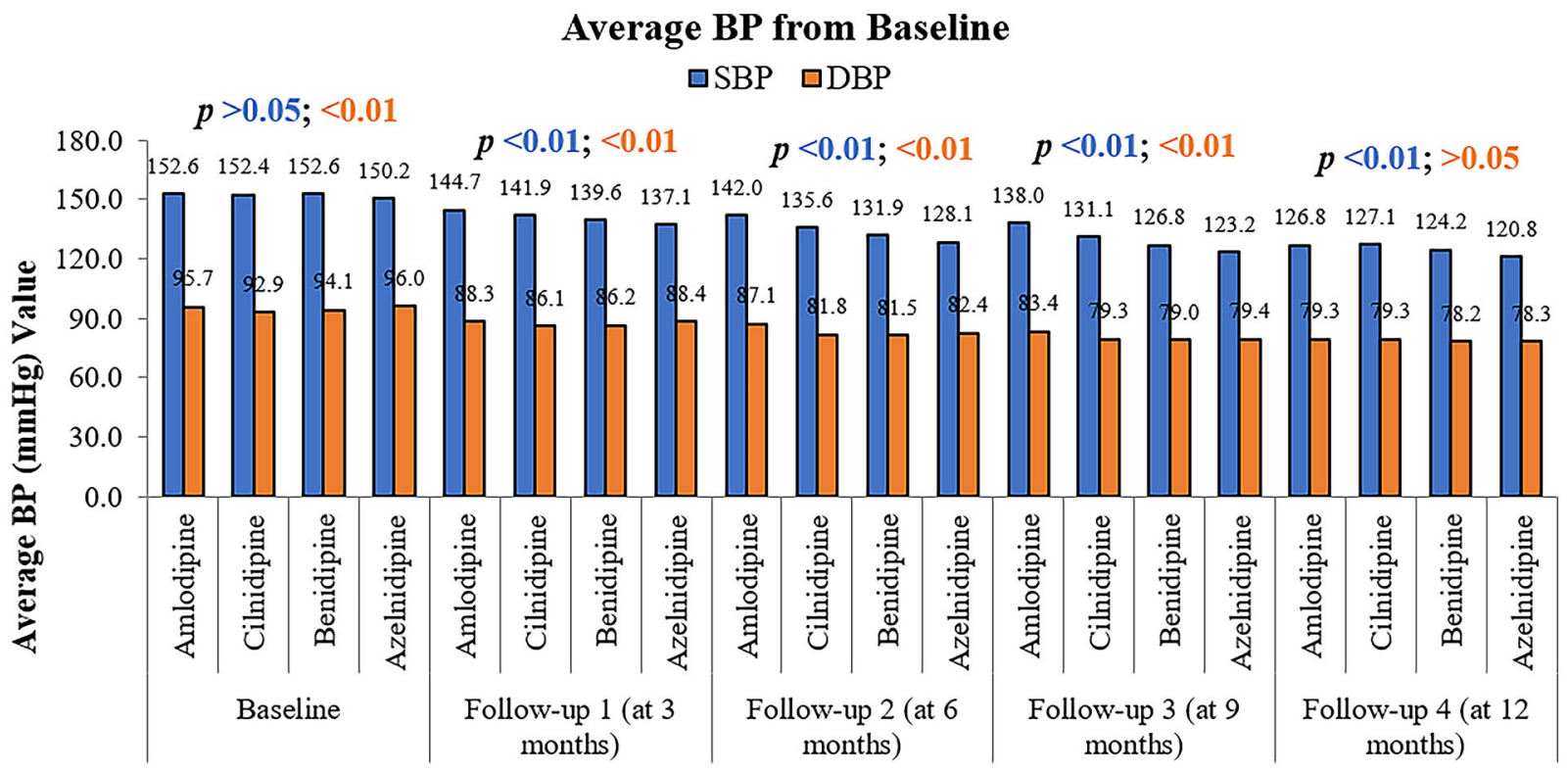

Fig. 4 Overall average BP from baseline to the end of the study

\section{Potency - Change in BP (mmHg) Per mg Dose of CCB}

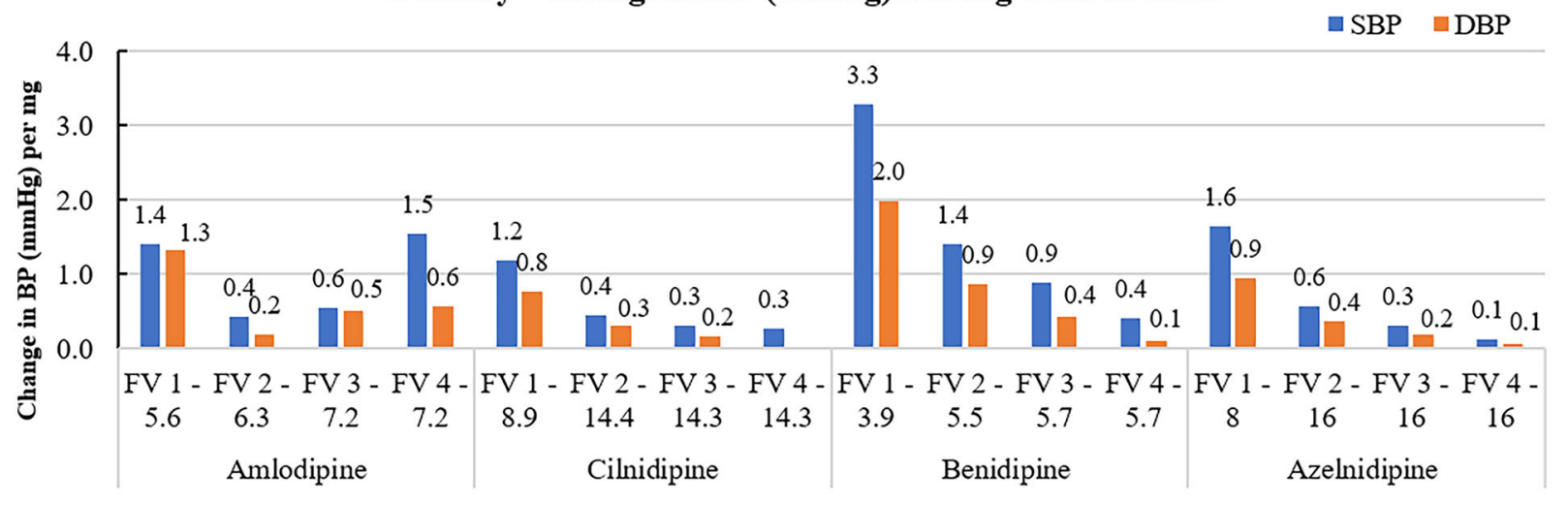

Mean Doses (mg) at Follow-up Visits (FV)

Fig. 5 Change in blood pressure per mg dose of each $\mathrm{CCB}$ 
Table 3 Change in antihypertensive therapy at the end of the study $(N=324)$

\begin{tabular}{|c|c|c|c|c|}
\hline Parameter & $\begin{array}{l}\text { Amlodipine } \\
(N=91) \\
n(\%)\end{array}$ & $\begin{array}{l}\text { Cilnidipine } \\
(N=90) \\
n(\%)\end{array}$ & $\begin{array}{l}\text { Benidipine } \\
(N=70) \\
n(\%)\end{array}$ & $\begin{array}{l}\text { Azelnidipine } \\
(N=71) \\
n(\%)\end{array}$ \\
\hline $\begin{array}{l}\text { Total \% of patients who continued the } \\
\text { prescribed CCB therapy }\end{array}$ & $64(69.57)$ & $31(34.07)$ & $55(78.57)$ & $9(12.68)$ \\
\hline $\mathrm{CCB}$ drug discontinued ${ }^{\mathrm{a}}$ & $1(1.09)$ & $1(1.10)$ & $2(2.86)$ & $2(2.82)$ \\
\hline Change in dose from baseline & $27(29.30)$ & $59(64.84)$ & $13(18.57)$ & $60(85.71)$ \\
\hline Other antihypertensive drug added & $12(13.04)$ & $9(9.89)$ & $0(0)$ & $9(12.68)$ \\
\hline $\mathrm{ARB}$ & $7(7.61)$ & $4(4.44)$ & $0(0)$ & $7(9.86)$ \\
\hline Beta blocker & $5(5.43)$ & $4(4.44)$ & $0(0)$ & $0(0)$ \\
\hline Alpha blocker & $1(1.09)$ & $2(2.22)$ & $0(0)$ & $0(0)$ \\
\hline Diuretic & $0(0)$ & $0(0)$ & $0(0)$ & $2(2.82)$ \\
\hline
\end{tabular}

${ }^{a}$ Discontinued due to pedal edema

azelnidipine, $13.14 \mathrm{mmHg}$ ), with the smallest reduction at the end of the study $(3.77,2.32$ and $2.00 \mathrm{mmHg}$ ). The difference per visit in mean reduction in $\mathrm{BP}$ at the end of the study across all groups was statistically significant $(p<0.01)$. Overall, at the end of the study, $>55 \%$ of patients in all four CCBs had achieved the target BP goal as per ESC/ESH 2018 guidelines.

The potency of CCBs was analyzed as per $\mathrm{mg}$ average dose reduction in mean BP units (Fig. 5). At follow-up visits 1 through 4 , the average doses were $5.59,6.33,7.25$ and $7.25 \mathrm{mg}$ for amlodipine; $8.9,14.39,14.34$ and $14.28 \mathrm{mg}$ for cilnidipine; $3.97,5.49,5.71$ and $5.71 \mathrm{mg}$ for benidipine; and 8, 16, 16 and $15.88 \mathrm{mg}$ for azelnidipine, respectively. As can be seen, from baseline to the end of the study, the average doses were increased within a range of 1.5 to $8 \mathrm{mg}$. The average reduction in BP was not improved to the same extent with increased (double) dose of cilnidipine, benidipine and azelnidipine. However, with amlodipine, the average reduction in BP was retained with an increase in the dose (Fig. 5). For example, the average reduction in SBP and DBP per $\mathrm{mg}$ for amlodipine dose of $5.59 \mathrm{mg}$ was 1.41 and $1.32 \mathrm{mmHg}$, respectively, and with an increased dose of $7.25 \mathrm{mg}, \quad 1.54$ and $0.57 \mathrm{mmHg}$.
Correspondingly, for cilnidipine, with an average dose of $8.9 \mathrm{mg}, 1.18$ and $0.76 \mathrm{mmHg}$ and with an increased dose of $14.28 \mathrm{mg}, 0.26$ and $0.01 \mathrm{mmHg}$ reduction was noted. For benidipine, with $3.97 \mathrm{mg}$ dose, 3.28 and $1.99 \mathrm{mmHg}$ and with increased dose of $5.71 \mathrm{mg}, 0.41$ and $0.11 \mathrm{mmHg}$ reduction was observed. Similarly, for azelnidipine, with $8 \mathrm{mg}$ dose, 1.64 and $0.94 \mathrm{mmHg}$ and with double the dose of $15.88 \mathrm{mg}, 0.13$ and $0.06 \mathrm{mmHg}$ reduction was noted.

\section{Tolerability Outcomes}

The percentage of patients who continued the prescribed CCB dose was highest for benidipine (79\%), followed by amlodipine (70\%), cilnidipine $(34 \%)$ and azelnidipine (13\%) (Table 3). Less than $3 \%$ of patients discontinued the treatment in all four groups. Other antihypertensive drugs were added for $13 \%$ of patients each in the amlodipine and azelnidipine groups, $10 \%$ of patients in the cilnidipine group and none in the benidipine group. Among other antihypertensives, angiotensin receptor blockers (ARBs; 4-10\%) were the most preferred, followed by beta-blockers $(4-5 \%)$ and other classes $(<3 \%)$. 


\section{DISCUSSION}

The clinical management of hypertension, a major cardiovascular risk factor, requires achieving strict and consistent blood pressure control through lifelong drug therapy [20, 21]. Management of hypertension also involves the renoprotective factor involved, as hypertension is both an effect and a cause of intraglomerular hypertension and glomerular hypertrophy. Though stringent BP control is a preventive factor in renal failure, ARBs and angiotensinconverting enzyme (ACE) inhibitors have proven to have renoprotective effects besides reduction in BP.

A wealth of evidence has long shown that CCBs are effective antihypertensives, and their use has extended beyond mere control of BP to their impact on cardiovascular safety. The oldgeneration CCBs were known to act only on afferent glomerular arterioles but not on efferent vessels, which led to intraglomerular hypertension. This limitation was improved in the new-generation dihydropyridine CCBs, which can dilate both vessels, similar to ACE inhibitors. The ancillary effect of CCBs stems from the inhibition of renal sympathetic nerve activity. This further triggers efferent arteriolar vasodilation and thus protects the glomeruli through the attenuation of glomerular hypertension $[9,10]$. However, comparative data on renal parameters for amlodipine with other CCBs (benidipine, cilnidipine and azelnidipine), particularly in the Indian population, are scarce. The current study provides a comprehensive analysis of the renal parameters for patients on amlodipine compared with other CCBs (benidipine, cilnidipine, and azelnidipine) in a range of doses in a real-world Indian setting.

Malleshappa and coworkers [18], in a study with 60 hypertensive Indian patients with chronic kidney disease, found that in the cilnidipine group, urinary albumin excretion decreased markedly, from $25.1 \pm 19.9 \mathrm{mg} / \mathrm{g} \mathrm{Cr}$ observed at baseline to $12.6 \pm 9.0 \mathrm{mg} / \mathrm{g} \mathrm{Cr}$ at 6 months. In the same group, serum creatinine levels increased from $1.75 \pm 0.30 \mathrm{mg} / \mathrm{dL}$ at baseline to $1.80 \pm 0.30 \mathrm{mg} / \mathrm{dL}$, and eGFR decreased from $52.9 \pm 11.7 \mathrm{~mL} / \mathrm{min}$ per 1.73 $\mathrm{m}^{2}$ at baseline to $49.8 \pm 8.7 \mathrm{~mL} / \mathrm{min}$ per 1.73 $\mathrm{m}^{2}$ at 6 months. However, no significant changes were observed in serum creatinine, eGFR or urinary albumin excretion in the current study. Nakamura et al. [16] observed only a slight change in serum creatinine and estimated glomerular filtration rates during a treatment period of 12 months between hypertensive patients treated with benidipine and amlodipine. Abe et al. [22] demonstrated differing action of amlodipine and azelnidipine on urinary albumin excretion among diabetic patients already treated with ARBs. In the present study, no significant change in mean serum creatinine or mean BUN was observed in the amlodipine group from the baseline to the end of the study period (12 months). Abe et al. [23] also reported no significant difference in serum creatinine level (a predictor of the decline of eGFR) during a treatment period of 16 weeks with azelnidipine and cilnidipine in hypertensive patients with type 2 diabetes. Though the study duration was shorter than the current study period of 54 weeks, the results are comparable, wherein the diabetes patients did not show a significant change or deterioration in renal parameter outcomes.

Nishida et al., in an EMR-based study on five CCBs (amlodipine, cilnidipine, benidipine, nifedipine and azelnidipine), showed no significant association between treatment duration and both mean eGFR and serum creatinine levels. In addition, the difference in the change in eGFR and serum creatinine levels was not significant among the five CCB groups for any treatment duration [24], and the results are in agreement with the present study. A common pattern observed in all the groups was an increase in the mean doses to the end of the study period. However, no significant change was observed in mean serum creatinine, eGFR or UACR values with increased dose across all the groups. Additionally, the duration of treatment with the same dose showed no effect on the three parameters.

In an EMR-based study in Indian hypertensive patients on amlodipine, Khan et al. [25] observed that the ESC/ESH 2018-recommended BP target $(\leq 130 / 80 \mathrm{mmHg})$ was achieved in 
$30.1 \%$ and $42.2 \%$ of patients for SBP and DBP, respectively. In the present study, $>55 \%$ of patients achieved the ESC/ESH 2018 and IGH IV guidelines-recommended $\mathrm{BP}$ goal at the last visit, with the highest percentage achieved in the amlodipine group (23\%) among all the CCBs compared (Supplementary Information). The differences between the percentage of patients achieving the BP goal among all groups were statistically significant $(p<0.05)$. Akade et al. [26], on the other hand, reported no significant difference in the antihypertensive efficacy of amlodipine versus cilnidipine $(p>0.05)$. Similar observations were made by Abbe et al. [23] in a comparative study of cilnidipine and azelnidipine. Shetty et al. [27], in a study conducted among 140 Indian patients, concluded that cilnidipine and amlodipine were equally effective in controlling blood pressure. In the present study, all four CCBs reduced $\mathrm{BP}$ from baseline to the end of the study, with varied extent of reduction from visit to visit. In the case of amlodipine, the extent of reduction in SBP and DBP increased gradually at each consecutive visit. The average effectiveness per $\mathrm{mg}$ dose of amlodipine showed a similar pattern.

Together, the results indicate that amlodipine has a greater effect at a lower dose and demonstrates long-lasting effectiveness, reduction in eGFR and UACR values, and no change in serum creatinine and other renal outcomes (BUN, sodium and potassium), making it the preferred choice over other CCBs. Additionally, the longer half-life, high bioavailability and affordability of amlodipine are an added advantage to its use as an antihypertensive for the Indian population.

\section{Limitations}

This retrospective study, like other retrospective RWE studies, has the drawback that patients were themselves responsible for adhering to treatment and complying with the given dosage regimen. As EMR contains only the prescription data, we cannot exclude the possibility of some patients not adhering to the prescription, leading to one or more missed doses, which could have contributed to a low observed therapeutic effect. CCBs are frequently used in combination with other antihypertensive agents such as ARBs, ACE inhibitors and antihypertensive diuretics. In this study, we focused on patients treated with CCB monotherapy. Consequently, many patients were excluded from the study population, according to the exclusion and inclusion criteria. Therefore, we may have systematically excluded patients with uncontrolled hypertension despite the use of $\mathrm{CCB}$ monotherapy, which potentially limits the generalizability of the findings.

\section{CONCLUSION}

In conclusion, amlodipine and other CCBs demonstrated good efficacy and similar effects on renal parameters from baseline to the end of the study. Amlodipine also showed higher potency by demonstrating greater BP reduction at a lower dose. Amlodipine can remain a preferred choice among CCBs, even with the advent of newer CCBs [28-30].

\section{ACKNOWLEDGEMENTS}

The authors thank Ashutosh Shrivastava, Aditi Vats, Dr. Saurav Deka, Dr. Srivani Palukuri and Ajendra P. Sharma from Sekhmet Technologies Private Limited (THB), India, for their support in the preparation of the manuscript.

Funding. Dr. Reddy's Laboratories funded the study and provided funding for the journal's Rapid Service Fee.

Authorship. All named authors meet the International Committee of Medical Journal Editors (ICMJE) criteria for authorship for this article, take responsibility for the integrity of the work as a whole, and have given their approval for this version to be published.

Disclosures. The authors Dr. Uday Jadhav, Dr. Padhinhare P. Mohanan, Dr. Alan Fernandes Almeida and Dr. Georgi Abraham are advisory board members for Dr. Reddy's Laboratories Ltd. 
Dr. Mohammed Yunus Khan, Dr. Kumar Gaurav, Seema Vikas and Dr. Amey Mane declare that they work in the Medical Affairs Department in Dr. Reddy's Laboratories Ltd, Hyderabad, India. Dr. Madhur Jain and Dr. Bhavesh Meel declare that there is no conflict of interest with regard to publication of this manuscript.

Author Contributions. The authors from Dr. Reddy's Laboratories contributed to conceptualizing the study hypothesis, design of the study, data analysis and interpretation of study outcomes. The advisory board members contributed significantly to revising the manuscript critically for important intellectual content and final approval and review. Dr. M. Jain and Dr. B. Meel provided the required study data inputs and important insights on patient outcomes.

Data Availability. The datasets generated and/or analyzed during the current study are available from the corresponding author on reasonable request.

Compliance with Guidelines. An independent ethics committee (IEC) located in Pune (Royal Pune Independent Ethics Committee, with registration number $\mathrm{ECR} / 45 / \mathrm{Indt} / \mathrm{MH} /$ 2013/RR-19), India approved the study protocol. This was a retrospective study and used anonymized data (existing medical records available as of the date of IEC submission) without any additional prospective components for research purposes. Hence, the process did not require us to obtain informed consent, since the study did not involve identifiable individuals. Accordingly, the IEC waived the requirement for informed consent form before the initiation of the data collection process for this study. The study was conducted in compliance with ethics guidelines and in accordance with the Helsinki Declaration of 1964 and its later amendments.

Open Access. This article is licensed under a Creative Commons Attribution-NonCommercial 4.0 International License, which permits any non-commercial use, sharing, adaptation, distribution and reproduction in any medium or format, as long as you give appropriate credit to the original author(s) and the source, provide a link to the Creative Commons licence, and indicate if changes were made. The images or other third party material in this article are included in the article's Creative Commons licence, unless indicated otherwise in a credit line to the material. If material is not included in the article's Creative Commons licence and your intended use is not permitted by statutory regulation or exceeds the permitted use, you will need to obtain permission directly from the copyright holder. To view a copy of this licence, visit http://creativecommons.org/licenses/by$\mathrm{nc} / 4.0 /$.

\section{REFERENCES}

1. 2016. GBoDS. http://ghdx.healthdata.org/gbdresults-tool. Accessed May 2020.

2. Williams B, Mancia G, Spiering W, Agabiti Rosei E, Azizi M, Burnier M, et al. 2018 ESC/ESH guidelines for the management of arterial hypertension: the Task Force for the management of arterial hypertension of the European Society of Cardiology (ESC) and the European Society of Hypertension (ESH). Eur Heart J. 2018;39(33):3021-104.

3. Ramakrishnan SZGGK, Rao JS, Zachariah G, Gupta K, Shivkumar Rao J, Mohanan PP, Venugopal K, Sateesh S, Sethi R, Jain D, et al. Prevalence of hypertension among Indian adults: results from the great India blood pressure survey. Indian Heart J. 2019;71(4):309-13.

4. Survey. DLHaF. https://data.gov.in/resources/ hypertension-age-18-years-and-above-dlhs-iv. Accessed May 2020.

5. Survey. NFH. http://rchiips.org/nfhs/abt.html. Accessed May 2020.

6. Collaborators GRF. Global, regional, and national comparative risk assessment of 84 behavioral, environmental and occupational, and metabolic risks or clusters of risks, 1990-2016: a systematic analysis for the Global Burden of Disease Study. Lancet. 2016;2017:1345-422.

7. Baekken MOISL, Oektedalen O. Microalbuminuria associated with indicators of inflammatory activity in an HIV-positive population. Nephrol Dial Transplant. 2008;23:3130-7. 
8. Stevens PE, Levin A. Evaluation and management of chronic kidney disease: synopsis of the Kidney Disease: Improving Global Outcomes 2012 clinical practice guideline. Ann Intern Med. 2013;58: 825-30.

9. Kishore S. A complete guide on the pharmacologic and pharmacotherapeutic aspects of calcium channel blockers: an extensive review. Int J Pharm Sci Res. 2019;10(11):4830-43.

10. Tiwaskar M, Langote A, Kashyap R, Toppo A. Amlodipine in the era of new generation calcium channel blockers. J Assoc Physicians India. 2018;660:59-64.

11. Judd ECD. Management of hypertension in CKD: beyond the guidelines. Adv Chronic Kidney Dis. 2015;22(2):116-22.

12. Ziakka S, Kaperonis N, Ferentinou E, Karakasis F, et al. Calcium channels blockers and progression of kidney disease. Renal Fail. 2009;29:1003-12.

13. Bakris GLWM, Secic M, Campbell B, Weis-McNulty A. Differential effects of calcium antagonist subclasses on markers of nephropathy progression. Kidney Int. 2004;65(6):1991-2002.

14. Appel LJ, Wright J Jr, Greene T, Agodoa LY, Astor BC, Bakris GL, et al. Intensive blood-pressure control in hypertensive chronic kidney disease. N Engl J Med. 2010;363(10):918-29.

15. Nishida Y, Takahashi Y, Tezuka K. Comparative effect of calcium channel blockers on glomerular function in hypertensive patients with diabetes mellitus. Drugs R D. 2017;17:403-12.

16. Nakamura T, Sato E, Fujiwara N, et al. Comparative effects of benidipine and amlodipine on proteinuria, urinary 8-OHdG, urinary L-FABP, and inflammatory and atherosclerosis markers in early-stage chronic kidney disease. Am J Med Sci. 2010;399(2): 157-63.

17. Dange SV, Sharma B, Kataria PP, Vaid R. Comparison of effects of benidipine and amlodipine on clinical and biochemical parameters in hypertensive patients: an observational study. Int J Basic Clin Pharmacol. 2017;6(9):2233-6.

18. Malleshappa P. Cilnidipine effectively reduces lowgrade albuminuria in hypertensive chronic kidney disease patients. Dial Traspl. 2013;34(1):2-6.

19. Tamargo J, Ruilope LM. Investigational calcium channel blockers for the treatment of hypertension. Expert Opin Investig Drugs. 2016;25(11):1295-309.

20. Romito RPMPF, Antonelli G, Pitzalis M, Rizzon P. Comparative effect of lercanidipine, felodipine, and nifedipine GITS on blood pressure and heart rate in patients with mild to moderate arterial hypertension: the Lercanidipine in Adults (LEAD) Study. J Clin Hypertens (Greenwich). 2003;5(4):249-53.

21. Pruijm MT, Maillard MP, Burnier M. Patient adherence and the choice of anti-hypertensive drugs: focus on lercanidipine. Vasc Health Risk Manag. 2008;4(6):1159-66.

22. Abe M, Okada K, Maruyama T, et al. Comparison of the antiproteinuric effects of the calcium channel blockers benidipine and amlodipine administered in combination with angiotensin receptor blockers to hypertensive patients with stage 3-5 chronic kidney disease. Hypertens Res. 2009;32:270-5.

23. Abe HMT, Yamamoto R, Komiya K, Kawaguchi M, Sakurai $Y$, et al. Comparison of effects of cilnidipine and azelnidipine on blood pressure, heart rate and albuminuria in type 2 diabetics with hypertension: a pilot study. J Diabetes Investig. 2013;4(2):202-5.

24. Nishida Y, Takahashi Y, Tezuka K, Takeuchi S, Nakayama T, Asai S. Comparative effect of calcium channel blockers on glomerular function in hypertensive patients with diabetes mellitus. Drugs R\&D. 2017;17(3):403-12.

25. Khan MY, Pandit S, Ray S, Mohan JC, Srinivas BC, et al. Effectiveness of amlodipine on blood pressure control in hypertensive patients in india: a realworld, retrospective study from electronic medical records. Drugs Real World Outcomes. 2020;7(4): 281-93.

26. Adake P, Somashekar HS, Rafeeq PM, Umar D. Comparison of amlodipine with cilnidipine on antihypertensive efficacy and incidence of pedal edema in mild to moderate hypertensive individuals: a prospective study. J Adv Pharm Technol Res. 2015;6(2):81-5.

27. Shetty K, Shetty R, Bairy L, Rao P, et al. A comparative study on clinical and biochemical parameters in amlodipine and cilnidipine treated hypertensive patients. J Clin Diagn Res. 2017;11(5):FC01-5.

28. Mula-Abed WAS, Al Rasadi K, Al-Riyami D. Estimated glomerular filtration rate (eGFR): a serum creatinine-based test for the detection of chronic kidney disease and its impact on clinical practice. Oman Med J. 2012;27(2):108-13.

29. Sharma S. Newer drug choices in hypertension treatment. Hypertension. 2020;6(2):70-3.

30. Yamagishi T. Beneficial effect of cilnidipine on morning hypertension and White coat effect in patients with essential hypertension. Hypertens Res. 2006;29:339-44. 